\title{
Understanding vernal keratoconjunctivitis in children
}

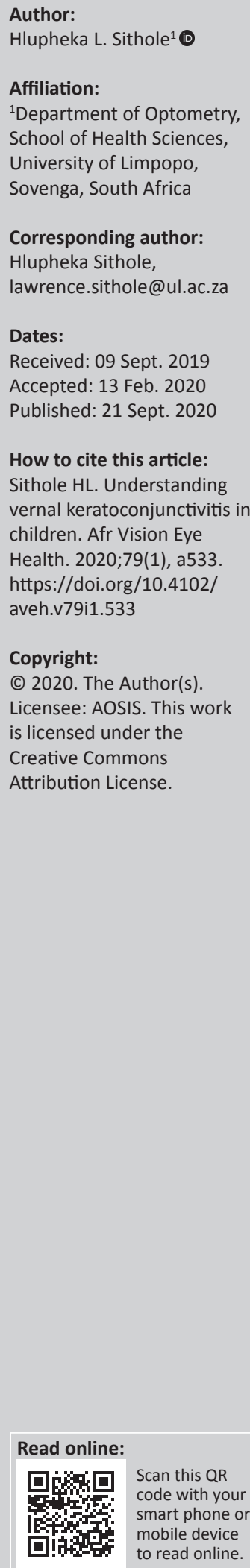

Background: Vernal keratoconjunctivitis $(\mathrm{VKC})$ is a public health problem that mostly affects children in warm subtropical climates. Unfortunately, the causative factors of the disease are not clearly defined, thus posing a serious management challenge to healthcare providers. It is therefore argued that understanding the pathogenesis of the disease and how various inflammatory cells affect the conjunctiva and the cornea may assist in the management of the disease.

Aim: As visual impairment and avoidable blindness are indicated, it is advisable for optometrists to understand the clinical presentation of this chronic condition in order to initiate appropriate interventions and/or immediate referrals where necessary.

Methods: A thorough literature search was conducted on peer-reviewed publications on VKC and children. All material obtained were then studied and the information extracted was used to document relevant information required for understanding VKC amongst children.

Results: The results in the studied material revealed that VKC was prevalent amongst children aged 2 to 18 years, affecting mostly male children of African and Indian origins. Different strategies of management of the disease have been proposed, including but not limited to explaining to parents the nature of the disease, environmental strategies and preventive measures as well as possible surgical intervention.

Conclusion: In view of the nature of this disease, healthcare providers should therefore seek to understand the history of the patient better when such patients present for their first consultation in order to develop a comprehensive management approach.

Keywords: vernal keratoconjunctivitis; chronic disease; children; allergy; public health.

\section{Introduction}

The last decade has witnessed a higher prevalence of childhood allergic diseases worldwide. . $2,3,4,5^{1}$ Childhood allergic diseases comprisea genetically heterogenous group of chronicimmunomediated diseases. ${ }^{6}$ This include, amongst others, ocular allergy, which is of five main types, namely seasonal allergic conjunctivitis, perennial allergic conjunctivitis, atopic keratoconjunctivitis (AKC), giant papillary conjunctivitis (GPC) and vernal keratoconjunctivitis (VKC). ${ }^{7}$ Atopic keratoconjunctivitis and VKC are chronic, bilateral and severe forms of allergic inflammation affecting the ocular surface. ${ }^{8}$ For the purpose of this article, only VKC is reviewed.

The name 'vernal' implies spring and youth, thus showing that, although VKC may become a chronic condition in some patients, it is a seasonal disease with exacerbations in warmer months (typically in spring) and affects mostly children and adolescents. ${ }^{9}$ It is a disease that was first identified more than 150 years ago as conjunctivitis lymphatica, and later as spring catarrh, phlyctenular pallida, circumcorneal hypertrophy, recurrent vegetative conjunctivitis, verrucous conjunctivitis and aestivus conjunctivitis; all these collectively describe various clinical presentations of the disease. ${ }^{10}$ In modern times, the disease's nomenclature is only known as VKC. It is conventionally described as an allergic, non-infectious, self-limiting ocular surface disorder that generally first occurs at a younger age as a recurrent chronic disorder of the conjunctiva and cornea with prevalence in children aged 2.5-18 years, and rarely in adults living in warm, dry and subtropical climates. ${ }^{11,12,13}$ Unfortunately, the long-standing presence of VKC amongst children can result in visual impairment and avoidable blindness. In the wake of the importance of this disorder as a public health concern, it is advisable for primary healthcare practitioners, such optometrists, to understand the clinical presentation of this condition in order to initiate appropriate interventions and/or immediate referrals where necessary. 


\section{Epidemiology}

The presence of VKC is a worldwide public health problem. ${ }^{14}$ Studies conducted in Europe, US as well as in the Mediterranean countries and the Middle East, ${ }^{14,15,16}$ have revealed that VKC accounts for $1 \%$ of eye diseases in most parts of the world and 3\% of important ocular diseases in tropical countries. ${ }^{15,16}$ According to Bremond-Gignac et al., ${ }^{17}$ VKC accounts for about 1.2 to 10.6 cases per 10000 population in Europe. In Africa, it accounts for $21 \%$ of general eye clinic consultations and is a major cause of hospital referrals. ${ }^{18}$ Bonini et al. ${ }^{19}$ state that VKC is predominantly a disease of children and adolescents as revealed in the Italian study, which showed that the mean age at diagnosis was usually between $6.8 \pm 5$ years and $11 \pm 5$ years. Only as low as $4 \%$ of patients diagnosed with the disease were older than 20 years when diagnosed initially. ${ }^{20}$

In an earlier study conducted amongst 40 black children aged between 2.5 and 18 years in Southern Africa, the peculiar nature of some forms of VKC was reported. ${ }^{11}$ Also, in a more recent study conducted in Ethiopia, $11.1 \%$ of children with an average age of $9.74 \pm 4$ years were diagnosed with VKC. ${ }^{21}$ Unfortunately, following a thorough literature search, the author could not determine the prevalence of VKC in South Africa. However, an unpublished study by Maifadi ${ }^{22}$ has reported incidences of children being diagnosed with VKC in eye clinics situated in Lebowakgomo and Zebediela hospitals in the Limpopo province. With South Africa having a semiarid climate, ${ }^{23}$ it is therefore not surprising that incidences of VKC are also reported amongst children. In these patients, male children are commonly affected than their female counterparts. ${ }^{19}$ Notably, dark-skinned persons from India and Africa have the highest incidence of limbal VKC. ${ }^{18}$

Vernal keratoconjunctivitis is also associated with atopic manifestations in about one-half of the affected individuals. ${ }^{24}$ The most common concomitant atopic diseases are asthma $(15 \%-64 \%)$, allergic rhinitis $(30 \%-49 \%)$ and eczema $(16 \%-$ $24 \%) .{ }^{19,20,25}$ In another earlier study, atopy was common in patients with palpebral or tarsal form of the disease compared with the limbal form. ${ }^{26}$ Moreover, VKC is also associated with a family history of other inflammatory diseases such as psoriasis and thyroiditis. ${ }^{27}$ However, the co-morbidity of other conditions in VKC patients has not been confirmed. ${ }^{9}$ Therefore, care must be taken to consider these atopic conditions when examining VKC patients.

\section{Pathophysiology}

Allergens are the main causative factors of allergies. ${ }^{28}$ Although it is reported that VKC is exacerbated by warm tropical climatic conditions, ${ }^{11,24,29}$ its pathophysiology remains largely unknown. ${ }^{29}$ Vernal keratoconjunctivitis patients have higher levels of inflammatory cells such as eosinophils in the tear glands and conjunctiva. ${ }^{30}$ Also, Immunoglobulin E (IgE) and T-cell-mediated mechanisms contribute in VKC, especially in the first two decades of life. ${ }^{31,32}$ This happens when an antigen is detected, thus causing lymphocyte activation, resulting in increased mucosal secretion in affected individuals. ${ }^{8,33}$ Other immunological pathways implicated in the aetiology of the disease include patients with higher number of activated CD4+ T-lymphocytes, thus indicating hypersensitivity reaction to an unknown pathogen. ${ }^{10}$ Higher levels of inflammatory cytokines IL-3, IL-4 and IL-5 have also been shown to be causative factors. ${ }^{34}$

Increased levels of $\operatorname{IgE}$ in the tears usually lead to a higher concentration of histamine in patients with VKC. ${ }^{35}$ It is possible that such an increase may also be associated with reduced inactivation of histamine by histaminase and possible increased local production by basal and mast cells, ${ }^{36}$ thus leading to itching as shown in Figure 1.

According to Leonardi et al., ${ }^{38}$ the superficial corneal epithelial layer, the basal epithelium as well as the stroma are affected in patients with VKC. Unfortunately, because corneal nerves have also been shown to be affected, ${ }^{38}$ this may lead to a possible visual impairment and as a resultant damage to the corneal stroma may lead to poor visual acuity (VA).

In another study conducted by Al-Hakami et al., ${ }^{39}$ it was considered that aberrations in the normal ocular surface microbiome may be contributing in the development of VKC. It was also found that Staphylococcus aureus was frequently isolated from the conjunctival specimens in patients with VKC and may be a contributory cause of disease progression, whilst Staphylococcus epidermidis was found in normal control patients. ${ }^{39}$ This further adds to the complexities of understanding the pathophysiology of VKC with much certainty.

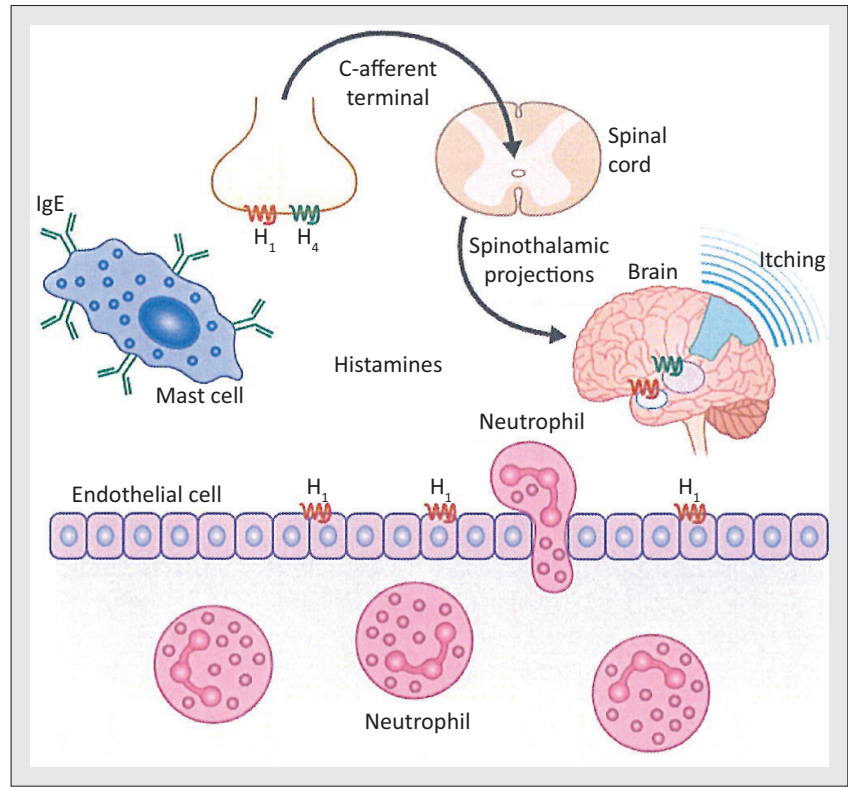

Source: Adapted from Connections between certain abiotic and biotic components of a granite catena ecosystem in Kruger National Park, sub-edited by Beanelri Janecke and Johan Van $\mathrm{Tol}^{37}$

FIGURE 1: Local reaction of Immunoglobulin E (IgE), histamine and mast cells as well as their interaction with local histamine $1(\mathrm{H} 1)$ and histamine $2(\mathrm{H} 2)$ receptors and the creation of the itching signal generated from the brain after local interaction with an antigen. 


\section{Other factors associated with vernal keratoconjunctivitis}

Allergic diseases such as VKC are reportedly associated with various factors, including academic status of the head of the house, monthly earnings, place of sleep, close contact with animals, dust exposure, history of childhood systemic allergy and history of family ocular allergy. ${ }^{21}$ Therefore, it is important to consider a detailed case history when patients present with symptoms of VKC so that offending allergens may be positively identified and appropriate management be initiated.

Furthermore, socioeconomic status has also been identified in the pathogenesis of VKC and this may include, amongst others, environmental, endocrine, racial and genetic factors. ${ }^{11,19}$ According to De Smedt et al., ${ }^{29}$ higher economic status is a predisposing factor for VKC. In support of this assertion, Nicolaou $^{40}$ reported that urbanisation was also considered a major risk factor for VKC amongst children in developing countries. This phenomenon is attributed to less childhood exposure to disease causing pathogens in the urban environments. ${ }^{41}$ Consequently, as a result of urban migration and urbanisation of communities, there is a preponderance of allergic diseases such as VKC. It is therefore not surprising that other studies show a rural environment to be protective against allergic diseases, although the mechanism thereof is unknown. ${ }^{42,43}$ However, it is possible that persistent exposure to offending allergens in such rural communities fortifies the immune system against diseases such as VKC.

According to Goldberg et $\mathrm{al}^{44}$ and Gordon, ${ }^{45}$ the larger the family size, the lower the prevalence of allergy, and this may suggest a possible protective advantage because of probably repeated exposure to allergens amongst siblings. Subbarao et al. ${ }^{46}$ and Garba et al. ${ }^{47}$ indicated that allergic diseases usually cluster in the same family. Interestingly, this is usually attributed to consanguineous marriages..$^{25}$ This further emphasises the need for a detailed case history when examining patients with VKC in order to fully understand any possible associated causative factors of the disease.

\section{Clinical presentation}

The clinical presentation of VKC is seen in three various forms, namely palpebral, limbal and mixed. ${ }^{8}$ In palpebral VKC, papillae greater than or equal to $1 \mathrm{~mm}$ are observed on the tarsal conjunctiva without involvement of the limbus. Other important symptoms may include foreign body sensation, redness of the conjunctiva, tearing, photophobia and sticky mucus discharge. ${ }^{13}$ On the other hand, in limbal $\mathrm{VKC}$, at least one of the following observations could be made: thickening, broadening and Horner-Trantas dots with itching sensation. Mixed VKC would have the presence of features of both limbal and tarsal VKC.,13

Although clinical presentations of VKC depend on the severity of the disease, ${ }^{30}$ almost all patients with this condition have ocular pruritus and would often present with symptoms of blurred vision $^{48}$ and watery eyes. ${ }^{31}$ Other typical clinical signs may include ptosis, blepharospasm, plagues and other conditions as seen in Figures 2-4. Some of these conditions may lead to opacification on parts of the cornea, thus resulting in poor functional VA.

On examination of patients with VKC, predominance of the upper tarsal and limbal signs could be seen. The upper tarsal papillae are discrete, enlarged $(>1 \mathrm{~mm})$ and give rise to a classic 'cobblestone' appearance with flattened tops as seen in Figure 4(b). It is sub-epithelial fibrosis resulting from papillae hypertrophy that causes increased eyelid thickening, thus resulting in ptosis as shown in Figure 5.

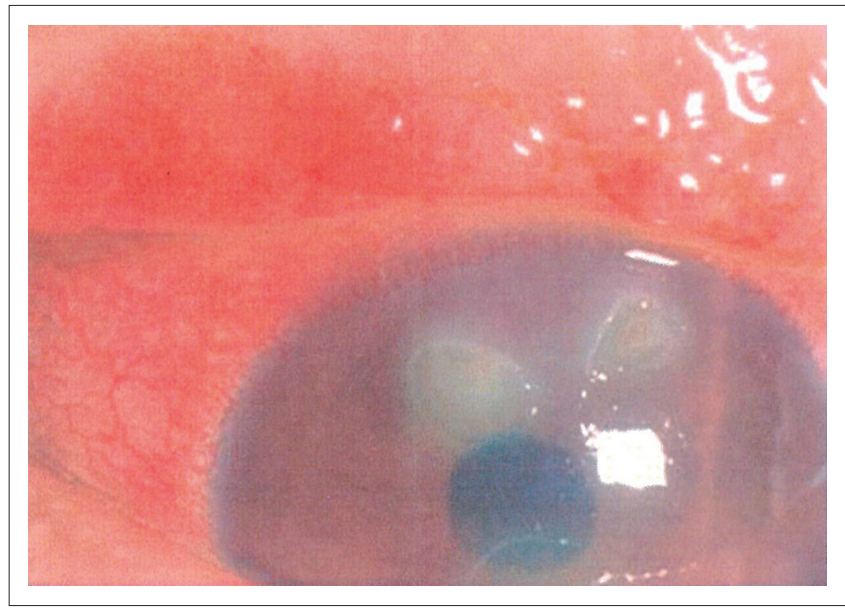

Source: Photo courtesy of Holland EJ, Mannis MJ, Lee WB. Ocular Surface Disease: Cornea Conjunctiva and Tear Film. Elsevier Inc.; 2013. https://doi.org/10.1016/B978-1-4557-2876$3.00055-9^{9}$

FIGURE 2: Two vernal shield ulcers with conjunctival injection.

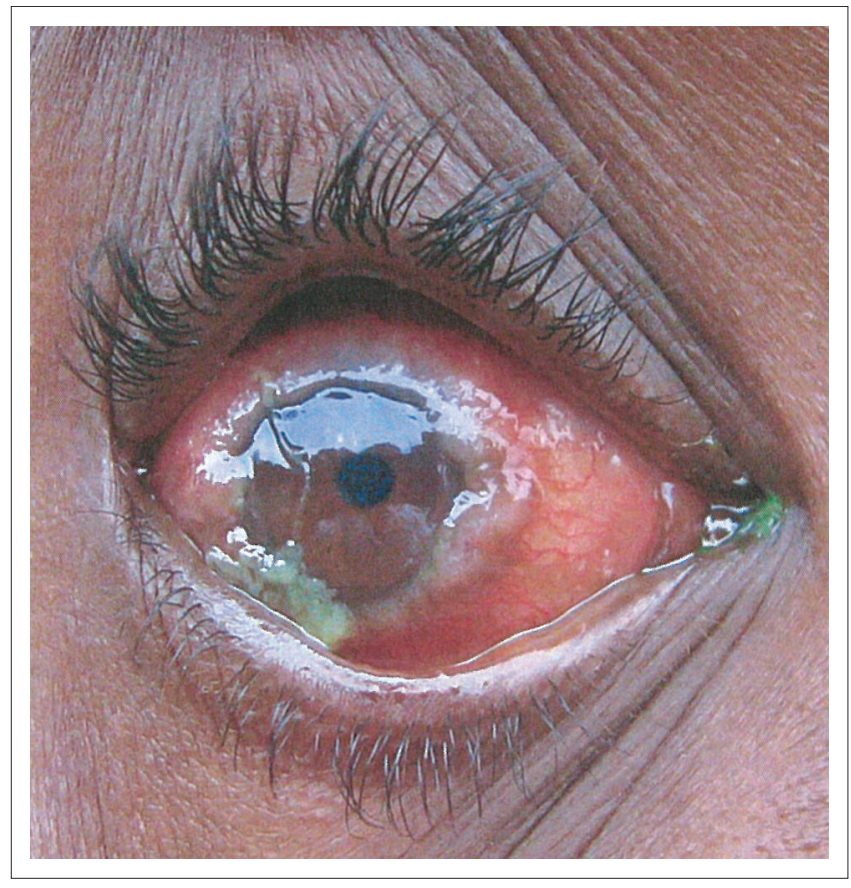

Source: Photo courtesy of De Smedt S, Nkurikiye J, Fonteyne Y, et al. Vernal keratoconjunctivitis in school children in Rwanda and its association with socio-economic status: A populationbased survey. Am J Trop Med Hyg. 2011;85(4):711-717. https://doi.org/10.4269/ ajtmh.2011.11-029129

FIGURE 3: Horner-Trantas dots as a sign of limbal vernal keratoconjunctivitis. 


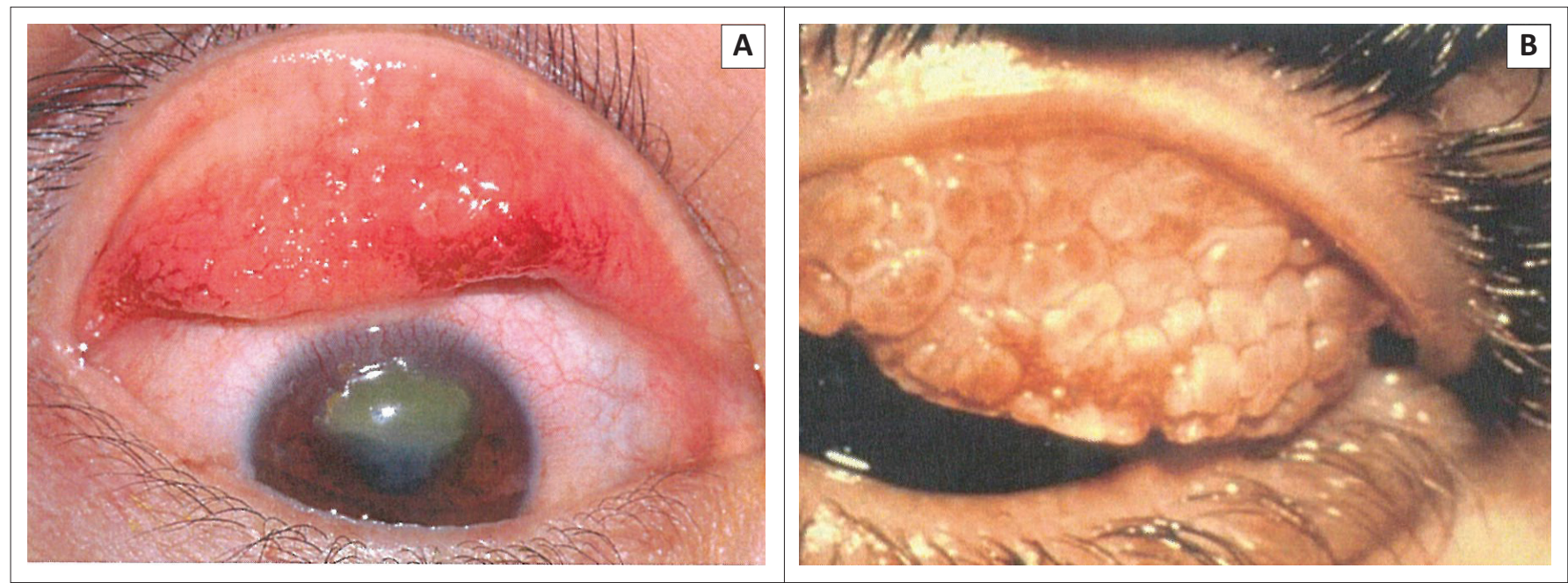

Source: Photo courtesy of Holsclaw DS, Whitcher JP, Wong IG, Margolis TP. Supratarsal injection of corticosteroid in the treatment of refractory vernal keratoconjunctivitis. Am J Ophthalmol. 1996;121(3):243-249. https://doi.org/10.1016/S0002-9394(14)70271-549 and Berdy GJ, Berdy SS. Ocular allergic disorders: Disease entities and differential diagnosis. Curr Allergy Asthma Rep. 2009;9:297-303. https://doi.org/10.1007/s11882-009-0042-1.12

FIGURE 4: (A) Giant papillae on the superior palpebral conjunctiva and a shield ulcer on the cornea with (B) giant papillae with flattened tops.

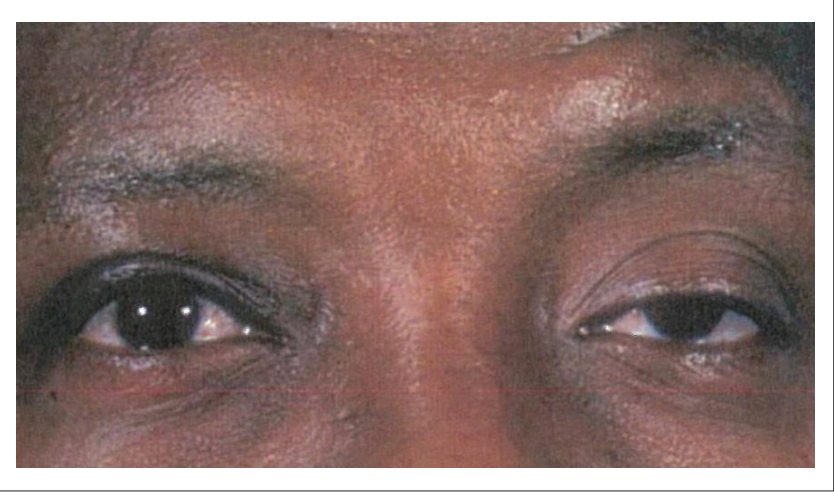

Source: Photo courtesy of Zoumalan Cl, Lisman RD. Evaluation and management of unilatera ptosis and avoiding contralateral ptosis. Aesthet Surg J. 2010;30:320-328. https://doi. org $/ 10.1177 / 1090820 \times 10374108^{50}$

FIGURE 5: Unilateral ptosis of the left eye that occurs as a result of vernal keratoconjunctivitis.

\section{Differential diagnosis}

It is reported that $35 \%$ of patients who present with red eye are more likely to have a diagnosis related to ocular allergic conjunctivitis. ${ }^{51}$ On the contrary, some of the patients whose clinical findings include red and itching eyes do not necessarily have ocular allergic disease. ${ }^{12}$ They may also be diagnosed with a different dormant external eye condition such as keratoconjunctivitis sicca or blepharitis. ${ }^{12}$ This therefore requires the examining optometrist to be an astute observer when taking case history and evaluating the patient.

The common presenting symptoms such as itching, burning eyes and redness pose a challenge in the accurate diagnosis of patients. ${ }^{12}$ It is therefore the responsibility of the examining optometrist to assess the symptoms and clinical signs in order to determine a proper treatment protocol. In most cases, it is not the symptoms and clinical signs that assist in the diagnosis, but rather it is the case history that may lead to a diagnosis. Therefore, when taking case history, the optometrist must ascertain that the patient's signs and symptoms occur during a season of common allergic reactions to offending antigens ${ }^{12}$ in order to conclusively come to a proper diagnosis.

Care must be taken that infectious causes include viral, bacterial and chlamydial form of microorganisms, and as such they should be excluded in the diagnosis of allergic conjunctivitis. Whereas viral and bacterial conjunctivitis present with an acute onset, chlamydial infections are usually laid-back, with a long standing history of red eye, tearing and foreign body sensation. Other major ocular conditions that could be confused with VKC are outlined in Table 1.

\section{Management}

As having a clear management process for VKC has reportedly been a challenge for ophthalmologists ${ }^{32}$ and possibly other healthcare professionals such as general practitioners, paediatricians, otolaryngologists and optometrists because of unclear pathogenesis of the disease and the often unsuccessful anti-allergic therapy, the use of a multifaceted approach in the management of VKC is recommended. These strategies may include a thorough explanation to parent as to the nature of the disease; possible extent of associated complications; environmental strategies and preventive measures; pharmacological therapy and possibly, surgical intervention. ${ }^{10}$

\section{Environmental strategies}

Avoidance of offending allergens and environmental factors that may exacerbate the disease by using protective spectacles when exposed to the sun, wearing of hats with visors, not using salty water as well as wearing goggles when swimming should be the primary approach in the management of VKC. ${ }^{8,33}$ Patient education and other preventive measures as shown in Box 1 also be considered. 
TABLE 1: Differential diagnosis of ocular allergy.

\begin{tabular}{lll}
\hline Feature & VKC & AKC \\
\hline Age of onset & Children between 2.5 and 18 years & Children and adults \\
Allergic mechanism & IgE- and non-IgE-mediated & IgE- and non-IgE-mediated \\
Gender predilection & Males & Males \\
Seasonal & Perennial/spring & Perennial \\
Horner-Trantas dots & Present with shield ulcers & Presence rare \\
Corneal Neovascularisation & None & Present \\
History of atopy & Asthma & Asthma, rhinitis \\
Discharge & Thick mucus discharge & Watery/mucous \\
Vision & Mild to severe & Spring \\
Papillary Hypertrophy & $7-$ mm - 8-mm limbus affected & Presence rare \\
Peri-ocular skin involvement & Oedema & None \\
Serum IgE & Variable & Dermatitis \\
Eosinophil in conjunctival swab & Characteristic (increased) & Greatly elevated \\
Goblet cells & Increased & Characteristic \\
Skin test & Non-specific & Decreased
\end{tabular}

Source: Adapted from Mashige KP. Ocular allergy. Health SA Gesondheid. 2017;22:112-122. https://doi.org/10.1016/j.hsag.2016.07.00152

VKC, Vernal keratoconjunctivitis; AKC, atopic keratoconjunctivitis; GPC, giant papillary conjunctivitis; IgE, immunoglobulin E.

BOX 1: Possible educative and preventive factors to consider in the management of vernal keratoconjunctivitis.

Considerations for patient education and preventive measures
Vernal keratoconjunctivitis is a chronic and recurrent condition that mainly
affects children but with a higher prevalence in males.
Rubbing of itchy eyes worsens the condition.
Salty water, sun and wind exacerbate the condition and should therefore be avoided.
Swimming goggles, protective spectacles and hats with visors should be used
when necessary.
Allergens that are known to be causative agents should be avoided.
Instillation of artificial tears and use of cold compresses may provide relief of the
symptoms.
Consider good hygienic practices by washing hands, face and hair regularly to
minimise contact with allergens.

Source: Adapted from Leonardi A. Management of vernal keratoconjunctivitis. Opthalmo Ther. 2013;2:73-88. https://doi.org/10.1007/s40123-013-0019- $\mathrm{y}^{32}$

VKC, Vernal keratoconjunctivitis.

\section{Pharmacological therapy}

Pharmacological interventions may be considered only after non-pharmacological agents have not provided sufficient relief from symptoms, and these could be applied topically or systemically. In this approach, treatment should be planned ahead of the season when allergic infections are most likely to occur. ${ }^{8}$ However, currently available topical drugs belong to several pharmacological classes, namely vasoconstrictors, antihistamines, mast cell stabilisers, dual acting agents (with antihistaminic and mast cell stabilising properties), nonsteroidal anti-inflammatory agents, corticosteroids and immunosuppressants. ${ }^{32}$ Use of anti-allergic therapeutic agents such as antihistamines, multiple action anti-allergic agents and mast cell stabilisers should be considered in order to achieve better clinical outcomes. ${ }^{8}$

It should also be noted that topical antihistamines competitively and reversibly block histamine receptors and relieve itching and redness albeit occasionally. ${ }^{53}$ The often unsuccessful measures of stabilising mast cells or histamine receptor antagonists alone have also been confirmed by Leonardi et al., ${ }^{38}$ who reported the inadequacy of controlling conjunctival inflammation and frequent involvement of
TABLE 2: Clinical grading of vernal keratoconjunctivitis and therapeutical approach.

\begin{tabular}{|c|c|c|}
\hline Clinical grade & Symptoms and clinical signs & Treatment \\
\hline 0 (Quiescent) & Absence of symptoms & No treatment \\
\hline 1 (Mild) & $\begin{array}{l}\text { Presence of symptoms with } \\
\text { no corneal involvement }\end{array}$ & Anti-allergic eye drops daily \\
\hline 2 (Moderate) & $\begin{array}{l}\text { Presence of symptoms: } \\
\text { Photophobia with no corneal } \\
\text { involvement }\end{array}$ & $\begin{array}{l}\text { Combined ant-allergic eye drops } \\
\text { daily }\end{array}$ \\
\hline 3 (Severe) & $\begin{array}{l}\text { Presence of symptoms: } \\
\text { Photophobia with mild-to- } \\
\text { moderate superficial punctate } \\
\text { keratopathy or corneal } \\
\text { involvement }\end{array}$ & $\begin{array}{l}\text { Anti-allergic eye drops daily with } \\
\text { pulsed low-dose topical steroid }\end{array}$ \\
\hline 4 (Very severe) & $\begin{array}{l}\text { Presence of symptoms: } \\
\text { Photophobia with diffused } \\
\text { superficial punctate } \\
\text { keratopathy or corneal ulcer }\end{array}$ & $\begin{array}{l}\text { Pulsed high-dose topical steroid } \\
\text { with eventual surgical removal of } \\
\text { corneal plagues }\end{array}$ \\
\hline
\end{tabular}

Source: Adapted from Leonardi A. Management of vernal keratoconjunctivitis. Opthalmo Ther. 2013;2:73-88. https://doi.org/10.1007/s40123-013-0019- $\mathrm{y}^{32}$ and Leonardi A. Management of vernal keratoconjunctivitis. Opthalmol Ther. 2013;2:73-88. https://doi. org/10.1007/s40123-013-0019-y

cornea using such measures. Unfortunately, currently available drugs seem to be merely palliative as they do not diminish the complex immune process that initiates and perpetuates inflammation of allergic ocular surface.

In the course of examining patients with VKC, it is important to consider clinical grading as outlined in Table 2 in order to determine the route of management to be administered.

Because of the chronicity of VKC, mast cell stabilising agents, such as cromolyn and lodoxamide, have been useful as a adjunctive therapy. ${ }^{12}$ These agents have shown to improve the symptoms and the associated corneal findings in patients treated for several weeks and they have been able to eliminate dependency on eye drops containing topical corticosteroids. ${ }^{12}$ If the disease is not controlled by using the aforementioned drugs, pulsed therapy of corticosteroid drops is recommended until the inflammation is controlled. ${ }^{8}$ Corticosteroids remain amongst the most potent pharmacological agents that could be used in the more severe variants of ocular allergy and are also more effective in the treatment of acute and chronic forms of VKC. ${ }^{4,55,56}$ However, in a study conducted by Holsclaw 
BOX 2: Showing a summary of practical management of vernal keratoconjunctivitis.

Summary of practical management of vernal keratoconjunctivitis (VKC)
Diagnosis should be accurate.
Educate on avoidance of the offending allergens and non-specific triggers (use
dark spectacles, hats with visors and swimming goggles).
Stress the importance of non-pharmacological treatment (lubricants, eyelid
hygiene, cold compresses).
Two or more topical, complementary drugs must be used in combination (mast
cell stabilisers + antihistamines or multiple action components).
Recommend an adequate frequency of instillation of topical drugs (4-6 times per day).
Warn against use and abuse of decongestant/vasoconstrictors.
Use topical corticosteroid formulations as pulsed therapy (3-5 days) to reduce flare-up.
Avoid corticosteroids as first-line of treatment of VKC.
Removal of corneal plagues is the only surgical procedure recommended in patients.

Source: Adapted from Leonardi A. Management of vernal keratoconjunctivitis. Opthalmo Ther. 2013;2:73-88. https://doi.org/10.1007/s40123-013-0019-y

VKC, Vernal keratoconjunctivitis.

et al. ${ }^{49}$ increase in intraocular pressure (IOP) was recorded in one of the 12 VKC patients. Therefore, care should be taken to always monitor IOP in patients taking corticosteroids for VKC treatment.

\section{Surgical interventions}

Surgical removal of corneal plagues is recommended to relieve severe symptoms and to allow for corneal reepithelisation. ${ }^{8}$ Cryotherapy and/or excision of giant papillae should be avoided as it may lead to corneal scarring, thus resulting in visual impairment. A summary of practical management of $\mathrm{VKC}$ is shown in Box 2.

\section{Conclusion}

Presence of ocular allergies have different pathophysiological pathways and mechanisms. Consequently, the management of ocular diseases such as VKC cannot only be limited to the use of various pharmacological agents, but rather the use of a multifaceted approach that may include a detailed understanding of the patient's socioeconomic status and case history as well as providing adequate expert advice on the avoidance of offending allergens as informed by the prevailing circumstances around the patient. As general practitioners and optometrists play a major role in primary healthcare services in South Africa, it should be of interest for these healthcare cadres to understand the best modalities that could be adopted for managing VKC patients as and when they present.

\section{Acknowledgements Competing interests}

The author declares that there is no financial or personal relationships that may have inappropriately influenced the writing of this article.

\section{Author contributions}

I declare that I am the sole author of this research article.

\section{Ethical consideration}

Ethical approval was not required for this Review article.

\section{Funding information}

This research received no specific grant from any funding agency in the public, commercial or not-for-profit sectors.

\section{Data availability statement}

Data sharing is not applicable to this article.

\section{Disclaimer}

The views and opinions of the author expressed in this article are that of the author and do not necessarily reflect the official policy or position of any affiliated agency of the author.

\section{References}

1. Ait-Khaled N, Odhiambo J, Pearce N, et al. Prevalence of symptoms of asthma, rhinitis and eczema in 13 to 14 years old children in Africa: The international study on asthma and allergies in childhood phase III. Allergy. 2007;62:247-258. https:// on asthma and allergies in childhood phase 11 .1111/j.1398-9995.2007.01325.x

2. Sanchez MC, Fernandez Parra B, Matheu V, et al. Allergic conjunctivitis. J Investig Allergol Clin Immunol. 2011;21:1-19.

3. Dennis RJ, Caraballo L, Garcia E, et al. Prevalence of asthma and other allergic conditions in Colombia 2009-2010: A cross-sectional study. BMC Pulm Med. 2012;12:17. https://doi.org/10.1186/1471-2466-12-17

4. De Marco R, Cappa V, Accordini S, et al. Trends in the prevalence of asthma and allergic rhinitis in Italy between 1991 and 2010. Eur Respir J. 2012;39:883-892. https://doi.org/10.1183/09031936.00061611

5. Hansen TE, Evjenth B, HoltJ. Increasing prevalence of asthma, allergic rhinoconjunctivitis and eczema among schoolchildren: Three surveys during the period 1985-2008. Acta Peadiatr. 2013;102:47-52. https://doi.org/10.1111/apa.12030

6. Hendaus MA, Jomha FA, Ehlayel M. Allergic diseases among children: Nutritional prevention and intervention. Ther Clin Risk Manag. 2016;12:361-372. https://doi. org/10.2147/TCRM.S98100

7. Hamral P, Dana R. Vernal keratoconjunctivitis [homepage on the Internet]. [cited 2019 Jun ]. Available from: https://www.uptodate.com/contents/vernalkeratoconjunctivitis/print

8. La Rosa M, Lionetti E, Reibaldi M, et al. Allergic conjunctivitis: A comprehensive review of the literature. Ital J Pediatr. 2013; 39:18. https://doi.org/10.1186/18247288-39-18.

9. Holland EJ, Mannis MJ, Lee WB. Ocular Surface Disease: Cornea, Conjunctiva and Tear Film. Elsevier Inc.; 2013. https://doi.org/10.1016/B978-1-4557-28763.00055-9

10. Leonardi A. Vernal keratoconjunctivitis: Pathogenesis and treatment. Prog Retin Eye Res. 2002;18:345-351. https://doi.org/10.1016/S1350-9462(02)00006-X

11. Dahan E, Appel R. Vernal keratoconjunctivitis in the black child and its response to therapy. Br J Opthalmol. 1983;67:688-692. https://doi.org/10.1136/bjo.67.10.688

12. Berdy GJ, Berdy SS. Ocular allergic disorders: Disease entities and differential diagnosis. Curr Allergy Asthma Rep. 2009;9:297-303. https://doi.org/10.1007/ s11882-009-0042-1

13. Addis H, Jeng B. Vernal keratoconjunctivitis. Clin Ophthalmol. 2018;12:119-123. https://doi.org/10.2147/OPTH.S129552

14. Hayilu D, Legesse K, Lakachew N, Asferaw M. Prevalence and associated factors of vernal keratoconjunctivitis among children in Gondar city, Northwest Ethiopia. BMC Ophthalmol. 2016;16:167. https://doi.org/10.11/s12886-016-0345-7

15. Khan MD, Kundi N, Saeed N, Gulab A, Nazeer AF. A study of 530 cases of vernal keratoconjunctivitis from the North West Frointer Province of Pakistan. Pakistan Ophthalmol. 1986;2:111-114.

16. Stephan JT, Ian AC, Mark W, David Y. Limbal vernal keratoconjunctivitis in the tropics. Rev Int Trachome. 1988;2:111-114.

17. Bremond-Gignac D, Donadieu J, Leonardi A, et al. Prevalence of vernal keratoconjunctivitis: A rare disease? Br J Ophthalmol. 2008:92(8):1097-1102. https://doi.org/10.1136/bjo.2007.117812

18. De Smedt S, Nkurikiye J, Fonteyne $Y$, et al. Vernal keratoconjunctivitis in school children in Rwanda and its association with socio-economic status: A populationbased survey. Am J Trop Med Hyg. 2011;85(4):711-717. https://doi.org/10.4269/ ajtmh.2011.11-0291

19. Bonini S, Bonini S, Lambiase A, et al. Vernal keratoconjunctivitis revisited. A case series of 195 patients with long-term follow-up. Ophthalmology. 2000;107:11571163. https://doi.org/10.1016/S0161-6420(00)00092-0

20. Leonardi A, Fregona IA, Plebani M, et al. Th1- and Th2-type cytokines in chronic ocular allergy. Graefes Arch Clin Exp Ophthalmol. 2006;244:1240. https://doi. org/10.1007/s00417-006-0285-7 
21. Alemayehu AM, Yibekal BT, Fekadu SA. Prevalence of vernal keratoconjunctivitis and its associated factors among children in Gambella Town, Southwest Ethiopia, June 2018. PLoS One. 2019;14(4):e0215528. https://doi.org/10.1371/journal. pone.0215528

22. Maifadi KV. Factors contributing to poor treatment outcomes of vernal keratoconjunctivitis in children in the Lepelle-Nkumpi municipality, Limpopo province, South Africa [Mini dissertation, master of public health]. Limpopo province, South Africa [Miversity of Limpopo; 2018.

23. Jury MR. Climate trends across South Africa since 1980. Water SA. 2017;43(4):297. https://doi.org/10.4314/wsa.v44i2.15

24. Lambiase A, Minchioti S, Leonardi A, et al. Prospective, multicentre demographic and epidemiological study on vernal keratoconjunctivitis: A glimpse of ocula surface in Italian population. Ophthalmol Epidemiol. 2009;16:38-41. https://doi. org/10.1080/09286580802573177

25. Ayuk AC, Eze JN, Edelu BO, Oguomu T. The prevalence of allergic diseases among children with asthma: What is the impact on asthma control in southeast Nigeria? Niger J Clin Pract. 2018;21:632-638. https://doi.org/10.4103/njcp.njcp_343_17

26. Tuft SJ, Dart JK, Kemeny M. Limbal vernal keratoconjunctivitis: Clinical characteristics and immunoglobulin E expression compared with palpebral vernal. Eye (Lond). 1989;3(Pt 4):420. https://doi.org/10.1038/eye.1989.63

27. Tesse R, Spadavecchia L, Fanelli $P$, et al. New insights into childhood vernal keratoconjunctivitis-associated factors. Pediatr Allergy Immunol. 2012;23:682. https://doi.org/10.1111/j.1399-3038.2012.01281.x

28. He S, Zhang H, Zeng X, Chen D, Yang P. Mast cells and basophils are essential for allergies: Mechanisms of allergic inflammation and a proposed procedure for diagnosis. Acta Pharmacol Sin. 2013;34:1270-1283. https://doi.org/10.1038/ aps.2013.88

29. De Smedt SK, Nkurikiye J, Fonteyne YS, et al. Vernal keratoconjunctivitis in schoo children in Rwanda. Ophthalmology. 2012;119:1766-1772. https://doi. org/10.1016/j.ophtha.2012.03.041PMID:22683059.

30. Pattnaik L, Acharya L. A comprehensive review on vernal keratoconjunctivitis with emphasis on proteomics. Life Sci. 2015;128:47-54. https://doi.org/10.1016/j Ifs.2015.01.040

31. Duke RE, Odey F, De Smedt S. Vernal keratoconjunctivitis in public primary schoo children in Nigeria: Prevalence and nomenclature. Epidemiol Res Int. 2016; ID 9854062. https://doi.org/10.1155/2016/9854062

32. Leonardi A. Management of vernal keratoconjunctivitis. Opthalmol Ther 2013;2:73-88. https://doi.org/10.1007/s40123-013-0019-y

33. Friedlaender MH. Ocular allergy. Curr Allergy Clin Immunol. 2011;11:477-482. https://doi.org/10.1097/ACl.0b013e32834a9652

34. Metz DP, Hingorami M, Calder VL, Buckley RJ, Lightman SL. T-cell cytokines in chronic allergic eye disease. J Allergy Clin Immunol. 1997;100:817-824. https:// doi.org/10.1016/S0091-6749(97)70279-3

35. Fujishima H, Saito I, Takeuchi T, Tsubota K. Immunological characteristics of patients with vernal keratoconjunctivitis. Jpn J Ophthalmol. 2002;46(3):244-248. https://doi.org/10.1016/S0021-5155(02)00481-1

36. George W, Ousler BS, Paulo J, et al. Methodologies for the study of ocular surface disease. Ocul Surf. 2005;3(3):143-154. https://doi.org/10.1016/S1542-0124(12)70196-9

37. Thurmond RL, Gelfand EW, Dunford PJ. The role of histamine $\mathrm{H} 1$ and $\mathrm{H} 2$ receptors in allergic inflammation: The search for new antihistamines. Nat Rev Drug Discov. 2008;7(1):41-53. https://doi.org/10.1038/nrd2465

38. Leonardi A, Bogacka E, Fauquert JL, et al. Ocular allergy: Recognisizing and diagnosing hypersensitivity disorders of the ocular surface. Allergy. 2012;67(11):1327-1337. https://doi.org/10.1111/all.12009
39. Al-Hakami AM, Al-Amri A, Abdulrahim I, Hamid ME. Is there an association between the presence of Staphylococcus species and occurrence of vernal keratoconjunctivitis? Saudi J Ophthalmol. 2015;29:255-258. https://doi. org/10.1016/j.sjopt.2015.05.002

40. Nicolaou N, Siddique N, Custovic A. Allergic disease in urban and rural populations: Increasing prevalence with increasing urbanization. Allergy. 2005;60:1357-1360. https://doi.org/10.1111/j.1398-9995.2005.00961.x

41. Okada $\mathrm{H}$, Kuhn $\mathrm{C}$, Feillet $\mathrm{H}$, Bach JF. The hygiene hypothesis for autoimmune and allergic diseases: An update. Clin Exp Immunol. 2010;160:1-9. https://doi. org/10.1111/j.1365-2249.2010.04139.x

42. Yamaneberhan $H$, Bekele Z, Venn A, et al. Prevalence of wheeze and asthma and relation to atopy in urban and rural Ethiopia. Lancet. 1997:350:85-90. https://doi. org/10.1016/S0140-6736(97)01151-3

43. Viinanen $A$, Munhbayarlah $\mathrm{S}$, Zevgee $\mathrm{T}$, et al. The protective effect of rural living against atopy in Mongolia. Allergy. 2007;62:272-280. https://doi.org/10.1111/ j.1398-9995.2007.01279.x

44. Goldberg S, Israeli E, Schwartz S, et al. Asthma prevalence, family size and birth order. Chest. 2007;131:1747-1752. https://doi.org/10.1378/chest.06-2818

45. Gordon BR. The allergic march: Can we prevent allergies and asthma? Otolaryngol Clin North Am. 2011;44:765-777. https://doi.org/10.1016/j. otc. 2011.03 .006

46. Subbarao P, Mandhane PJ, Sears MR. Asthma: Epidemiology, etiology and risk factors. CMAJ. 2009;181:181-190. https://doi.org/10.1503/cmaj.080612

47. Garba BI, Ibrahim M, Johnson AW. Socio-demographic and clinical characteristics of asthmatic children seen at Aminu Kano teaching hospital, Kano, Nigeria. Niger J Peadiatr. 2014;41:360-364. https://doi.org/10.4314/njp.v41i4.14

48. Kumar S. Vernal keratoconjunctivitis: A major review. Acta Ophthalmol. 2009;87:133. https://doi.org/10.1111/j.1755-3768.2008.01347.x

49. Holsclaw DS, Whitcher JP, Wong IG, Margolis TP. Supratarsal injection of corticosteroid in the treatment of refractory vernal keratoconjunctivitis. Am J Ophthalmol. 1996:121(3):243-249. https://doi.org/10.1016/S0002-9394(14) 70271-5

50. Zoumalan $\mathrm{Cl}$, Lisman RD. Evaluation and management of unilateral ptosis and avoiding contralateral ptosis. Aesthet Surg J. 2010:30:320-328, https://doi. org/10.1177/1090820X10374108

51. Granet D. Allergic rhinoconjunctivitis and differential diagnosis of the red eye. Allergy Asthma Proc. 2008;29:565-574. https://doi.org/10.2500/aap.2008. 29.3170

52. Mashige KP. Ocular allergy. Health SA Gesondheid. 2017;22:112-122. https://doi. org/10.1016/j.hsag.2016.07.001

53. Leonardi S, Marchese G, Marseglia GL, La Rosa M. Montelukast in allergic diseases beyond asthma. Allergy Asthma Proc. 2007;28(3):287-291. https://doi.org/10. 2500/aap.2007.28.2955

54. Spector SL, Raizman MB. Conjunctivitis medicamentosa. J Allergy Clin Immunol. 1994;94:134-136. https://doi.org/10.1016/0091-6749(94)90081-7

55. Dell SJ, Lowry GM, Northcut JA, et al. A randomized, double-masked, placebocontrolled parallel study of $0.2 \%$ loteprednoletabonate in patients with seasonal allergic conjunctivitis. J Allergy. 1998;102:251-255. https://doi.org/10.1016/ S0091-6749(98)70094-6

56. Fan DS, Yu CB, Chiu TY, et al. Ocular hypertensive and anti-inflammatory response to rimexolone therapy in children. Arch Ophthalmol. 2003;121:1716-1721. https://doi.org/10.1001/archopht.121.12.1716 